\title{
CRIMINALIZAÇ̃̃O E PERMISSIVIDADE: A DUPLA FACE DO ESTUPRO NAS SOCIEDADES PATRIARCAIS
}

\author{
CRIMINALIZATION AND PERMISSIVENESS: THE DOUBLE FACE OF RAPE IN PATRIARCHAL SOCIETIES
}

\section{RESUMO}

Diariamente, mulheres sofrem violência sexual em todo o mundo. Nas sociedades patriarcais, desde que o estupro foi criminalizado, um paradoxo se torna cada vez mais evidente: enquanto o Direito Penal avança na proteção da dignidade sexual feminina, com o endurecimento da pena aos agressores, uma embrenhada permissividade cultural à violação dos corpos femininos contrapõe-se à legislação. Este artigo investiga esse antagonismo, analisando, primeiramente, a relação que se estabelece entre masculinidade e violência. Na sequência, aborda, sob uma perspectiva histórica, a proibição do gozo feminino, a promoção da culpa e a maneira como esses fatores operam para a perpetuação da prática do estupro, evidenciando, entre outros pontos, que nem sempre as sociedades ocidentais se estruturaram sobre bases patriarcais, o que permite a visualização da possibilidade de se transformar a atual realidade. Por último, analisa-se a evolução da proteção da mulher pelo Estado em um contexto social ainda fortemente marcado pelo sexismo e pela opressão.

Palavras-chave: Estupro. Violência contra a mulher. Desigualdade de gênero. Direito Penal.

\begin{abstract}
Everyday women suffer sexual violence around the world. In patriarchal societies, since rape has been criminalized, a paradox has become increasingly evident: as criminal law advances in the protection of female sexual dignity, with the hardening of punishment for perpetrators, a deep cultural permissiveness to the violation of female bodies counteracts comply with the legislation. This article investigates this antagonism by first analyzing the relationship between masculinity and violence. It then addresses, from a historical perspective, the prohibition of female pleasure, the promotion of guilt, and how these factors operate to perpetuate the practice of rape, evidencing, among other points, that western societies are not always structured on patriarchal bases, which allows the visualization of the possibility of transforming the current reality. Finally, it analyzes the evolution of state protection of women in a social context still strongly marked by sexism and oppression.
\end{abstract}

\section{Thaís Ferreira Dutra}

Mestre em Direito pela Universidade Federal de Minas Gerais, analista do Ministério Público de Minas Gerais (MPMG). E-mail: thaisfdutra@yahoo.com.br

Tereza Cristina Sorice Baracho Thibau

Professora Associada na Faculdade de Direito da UFMG, Doutora em Direito e Processo Coletivo. E-mail: tthibau@gmail.com 
Keywords: Rape. Violence against women. Gender Inequality. Criminal law.

\section{Introdução}

Sentados em uma ampla sala de julgamento encontram-se dezenas de militares acusados pelo estupro de pelo menos 76 mulheres e meninas (HRW, 2015) em 2012, na cidade de Minova, na República Democrática do Congo. Uma a uma, com os rostos vendados por um tecido preto, que deixa de fora apenas os olhos, as vítimas são levadas à frente do tribunal para narrar à corte as atrocidades sexuais vivenciadas por elas em suas aldeias, durante o período de guerra no país. Os olhares, profundamente marcados pela dor, despertam angústia e indignação em qualquer espectador minimamente sensível aos direitos humanos. As falas, há muito tempo silenciadas, apresentam-se, ali, como a única oportunidade de se denunciar as violações sofridas e de serem ouvidas.

A cena, forte, sufocante e emblemática da situação de menosprezo e violência vivenciada por milhões de mulheres em todo o mundo, faz parte do curta-documentário norte-americano The Testimony (2015), produzido e dirigido pela cineasta Vanessa Block. Ele retrata o "Julgamento Minova”, realizado em 2014 pelo exército da República Democrática do Congo, para processar os estupros cometidos pelas tropas do governo contra a população feminina local, naquele que foi considerado o maior julgamento de estupro na história do país.

Os réus são oficiais e soldados que, em 2012, após serem expulsos por rebeldes da cidade de Goma, no leste do Congo, retiraram-se, envergonhados e desmoralizados, para Minova, onde, sistematicamente, estupraram concidadãs. A atrocidade provocou indignação internacional e reforçou a imagem do país como referência mundial de estupro'. O que o documentário revela, no entanto, é, lamentavelmente, apenas uma amostra da realidade de violências enfrentadas todos os dias pela população feminina no mundo.

"O estupro é uma arma de guerra”, afirmam, recorrentemente, a jurisprudência e a doutrina internacionais contemporâneas, a respeito desta modalidade de crime; informando, com a expressão, sobre o uso da prática como estratégia de poder, de dominação e de humilhação pelos combatentes. No âmbito das Relações Internacionais, há também um campo consolidado de análises sobre o conceito, que, por sua vez, demonstram que as tentativas de destruição do sujeito feminino, neste cenário, ocorrem de maneira dupla: na condição de indivíduo e de membro de um grupo étnico que pertence a uma nação (Casagrande et al., 2015: 135).

De fato, não há dúvida sobre a estreita relação existente entre as guerras e a violência sexual contra as mulheres. Há que se notar, porém, que a guerra em questão

1 De acordo com uma pesquisa realizada pelo The Journal of the American Medical Association, em 2010, 39,7\% das mulheres na região leste do Congo afirmaram ter sofrido um estupro na vida. Disponível em: $<$ https://jornalggn.com.br/politica/internacional-politica/a-violencia-contra-mulheres-no-congo/>. Acesso em: 10 jul. 2019. 
não se refere somente aos conflitos bélicos, como se poderia pensar em um primeiro momento. A batalha em que se insere a impiedosa prática do estupro, em muitos países, é cotidiana, silenciada, silenciosa e estruturada sobre aspectos simbólicos que, muitas vezes, escapam aos olhares mais pragmáticos.

De acordo com o Anuário Brasileiro de Segurança Pública 2019, nos anos de 2017 e 2018, o Brasil registrou um total de 127.585 ocorrências de estupro e de estupro de vulnerável ${ }^{2}$, sendo $81,8 \%$ das vítimas do sexo feminino, o que confere à desigualdade de gênero grande relevância na análise sobre a violência sexual.

Os dados revelam, ainda, que $63,8 \%$ desses crimes são cometidos contra vulneráveis. Em relação ao vínculo com o abusador, 75,9\% das vítimas possuem, conforme a pesquisa, relação de proximidade com o agressor, como de parentesco, companheirismo, amizade, entre outras (FBSP, 2019: 115-116).

Acerca do crescimento dos registros de violência sexual no país, o Atlas da Violência 2018, de autoria do Instituto de Pesquisa Econômica Aplicada (Ipea) e do Fórum Brasileiro de Segurança Pública (FBSP), informa que o número de notificações de estupro feitas ao Sistema Único de Saúde (SUS) aumentou 90,2\% em cinco anos, passando de 12.087 casos informados em 2011 para 22.918 em 2016.

Os pesquisadores responsáveis pelo estudo acreditam que a alta da violência contra a mulher no Brasil pode decorrer de três fatores: do aumento da prevalência do crime; do aumento na taxa de notificação a reboque das inúmeras campanhas feministas e governamentais; ou da expansão e do aprimoramento dos centros de referência que registram as notificações (IPEA, 2018: 58).

É necessário observar que, apesar do crescimento dos registros, a subnotificação dos casos de violência sexual ainda é uma realidade que impede a visualização do quadro na sua integralidade. Nos Estados Unidos, por exemplo, apenas 15\% do total dos estupros são reportados à polícia. Caso a taxa de subnotificação brasileira fosse igual à norte-americana, ou girasse em torno de 9o\%, a prevalência dos crimes dessa natureza, no Brasil, seria de 300 mil a 500 mil a cada ano (IPEA, 2018).

Para Susan Brownmiller, o estupro é "um processo consciente de intimidação pelo qual todos os homens mantêm todas as mulheres em um estado de medo" (Brownmiller, 1993: 15). Essa afirmação, que será examinada ao longo do artigo, evidencia que vivemos em estado permanente de guerra entre o feminino e o masculino, no qual coexistem inúmeros paradoxos, como, talvez o mais evidente, a criminalização da violência sexual contra a mulher, na maioria dos países, e a simultânea permissividade cultural à violação da liberdade e da dignidade desse grupo.

Assim, a mesma sociedade que prepara meninos para serem viris e dominadores, pune os homens pela prática da violência sexual. A mesma sociedade que educa meninas para o silêncio, mantendo-as distantes da sua sexualidade e de suas possibilidades de crescimento, culpabiliza mulheres por sofrerem violência e

2 O estupro contra vulnerável é aquele que tem como vítima pessoa com menos de 14 anos, que é considerada juridicamente incapaz para consentir relação sexual, ou pessoa incapaz de oferecer resistência, independentemente de sua idade, como alguém que esteja sob efeito de drogas, enfermo ou ainda pessoa com deficiência, como determina a Lei 12.015/o9. 
dificulta o acolhimento delas, quando violentadas. Que papel cumpre o Direito Penal neste contexto? Ele tem força de, sozinho, eliminar uma cultura de estupro há tanto tempo instalada?

A fim de estimular essas reflexões, o presente trabalho apresenta, inicialmente, uma análise do que Saffioti denomina "o poder do macho" (Saffioti, 2001) nas sociedades patriarcais, com enfoque nos estupros praticados durante as guerras, a fim de se expor a estreita relação entre masculinidade e violência. Na sequência, abordase, sob uma perspectiva histórica, a proibição do gozo feminino, a promoção da culpa e a maneira como esses fatores culturais operam para a perpetuação da prática do estupro. E, por último, analisa-se o paradoxo criminalização x permissividade, presente na maioria das sociedades patriarcais, nas quais o Direito Penal avança, ainda que lentamente, no sentido de resguardar as liberdades femininas, ao mesmo tempo em que as estruturas sociais mantêm as mulheres na condição de objeto, subjugadas à força, à vontade e ao prazer dos homens.

\section{O poder do macho}

Há séculos, pesquisadores têm buscado compreender a origem de comportamentos sexuais considerados "desviantes" na sociedade, entre eles, os praticados com violência, como o estupro. As primeiras teorias, produzidas no final do século XIX, procuravam associar a presença de determinadas características fisiológicas à propensão para condutas sexuais abusivas, como a teoria desenvolvida pelo psiquiatra italiano Cesare Lombroso. Outras buscaram entender a violência sexual a partir de anomalias cromossômicas e genéticas. No entanto, nenhuma delas estabeleceu, suficientemente, um nexo de causalidade entre alguma anomalia natural e condutas sexuais violentas (Iennaco, 2017: 158-159).

Atualmente, a violência sexual é vista como um fenômeno multifatorial, determinada, em grande medida, por aspectos culturais, especialmente pela constituição do masculino e do feminino. $O$ gênero, neste sentido, é tido como uma categoria de análise que afirma a historicidade das distinções sociais entre os sexos, uma vez que as relações de gênero não são um aspecto permanente, fixo e imutável da condição humana, como ensina Joan Scott (1995: 21).

Autoras feministas, de modo geral, vêm relacionando a violência contra a mulher às estruturas sociais patriarcais, que colocam os homens em posição de superioridade, de autoridade e de domínio em relação às mulheres. Sobre essas bases é que se constituíram o mito da virilidade e a ideia de uma masculinidade única. Isto é, conforme concepções enraizadas nas sociedades patriarcais, para ser homem, é preciso ser viril, dominador, corajoso, racional, não demonstrar fraqueza, nem qualquer outra emoção que possa ameaçar sua posição de poder. $\mathrm{O}$ falo, ou pênis, neste contexto, assume lugar de destaque, representando o símbolo da própria masculinidade. Conforme Saffioti (2001: 19): 
Lamentavelmente, inclusive para os próprios homens, a sexualidade masculina foi culturalmente genitalizada. Ou seja, o processo histórico conduziu o homem a concentrar sua sexualidade nos órgãos genitais. [...] Dessa concepção da sexualidade na genitália deriva a expressão "falocracia", ou seja, o poder do macho. Pode-se também inverter o raciocínio e afirmar que a consolidação da supremacia masculina, ao longo de milênios de história, conduziu ao endeusamento do pênis.

É necessário voltar os olhos ao passado para se compreender a origem da supremacia masculina e do culto ao falo, pois nem sempre as sociedades ocidentais se estruturaram sobre bases patriarcais. Conforme Muraro (1989: 12), no período paleolítico, os agrupamentos humanos eram nômades e matricêntricos ${ }^{3}$, caracterizados pela cooperação e pela igualdade de tarefas entre homens e mulheres. Não havia coerção ou centralização de funções, mas rodízio de lideranças. Os princípios feminino e masculino governavam juntos. Com a escassez dos recursos vegetais naturais e dos pequenos animais, começa-se a caça sistemática aos grandes animais, e, com ela, a supremacia masculina, graças à necessidade da força física e à competitividade entre os grupos, na busca por novos territórios. Os homens mais valorizados passam a ser os guerreiros ${ }^{4}$.

A lei do mais forte se consolida com a chegada do período neolítico, quando o homem toma consciência de sua função biológica reprodutora, já que até então acreditava-se que as mulheres engravidavam dos deuses. Cientes de sua potência sexual, os homens passam a controlar a sexualidade feminina, o que fortaleceu a relação de dominação-subjugação já engendrada. Com a fixação das tribos em determinados locais, o desenvolvimento da agricultura, a criação de animais e o início da divisão de trabalho, os papéis sociais de homens e mulheres ficam ainda mais definidos e naturalizados. Aos homens, são atribuídas as tarefas que garantem a sobrevivência da tribo e, posteriormente, a da família, e às mulheres, a reprodução e a criação dos filhos, traços presentes até hoje nas sociedades ocidentais. De um lado, são fixados, portanto, o poder de decisão, a ação, a força e o controle, e, do outro, a passividade, a sensibilidade e a fraqueza.

Rodrigo Iennaco aponta a existência de uma "normatização informal machista, de incidência universal, que se assentou na valorização positiva da agressividade como realização enfática da virilidade”. Haveria, segundo ele, um "código social em favor da virilidade masculina como projeção aceita da agressividade antropológica” (Iennaco, 2017: 179). É esse código que justifica as

3 São chamados matricêntricos os agrupamentos caracterizados pela cooperação, onde a mulher ocupa lugar central e as formas de associação entre homens e mulheres não incluem nem a transmissão do poder, nem a da herança.

4 Para os adeptos do relativismo cultural, é impossível afirmar que todos os povos, em todas as localidades do planeta, viveram da mesma forma em determinado período. Por isso, quando se remonta à história neste trabalho, estão sendo consideradas as características sociais predominantes, conforme os estudos antropológicos. 
ações violentas dos homens, atribuindo a virilidade, a agressividade e a falta de controle sobre os impulsos sexuais à natureza masculina. Esse regramento não aceita o "não" da mulher como resposta ao homem. Há uma expectativa da moralidade social, que atribui ao macho a transformação do "não" inicial em "sim", para honrar seu papel de conquistador.

No entanto, apesar de se mostrar forte, a virilidade masculina, quando investigada, revela-se, antagonicamente, bastante frágil. Conforme Rita Laura Segato, o violador não atua porque detém o poder, mas justamente porque deve estar constantemente obtendo-o, uma vez que o status de homem, por não ser inato, está sempre em risco e deve ser conquistado todos os dias (Segato, 2003:37)5. "O problema da violência contra a mulher se torna, assim, o problema da masculinidade, e é isso que deve ser investigado para se compreender o primeiro" (Plummer, 1984: 53). Destarte, de acordo com o psicanalista Serge Hefez:

Quanto mais lhe apresentam [aos meninos] o feminino como diferente, perigoso, castrador e devorador, ou inferior e submisso, mais ele desenvolverá em relação às mulheres e à sua própria parte feminina uma violência e um desprezo que o levam a uma diferenciação sistemática, à recusa de se misturar, ao ódio às mulheres e aos homossexuais, as duas figuras malditas, mas também fascinantes da passividade penetrada. O meio mais seguro para se proteger contra isso é neutralizar os indivíduos passivos penetráveis, considerando-os objetos com que se goza sem nada trocar com eles (HEFEZ, 2013: 76-77).

Neste cenário de imposição social de uma masculinidade violenta, o estupro constitui uma busca pelo poder e pela dominação nas relações entre o masculino e o feminino. Diferentemente do que uma análise superficial levaria a pensar, ele não se reduz, no entanto, a um ato de luxúria, como se estupradores fossem simplesmente pessoas que não conseguem controlar seus desejos sexuais. Os motivos que levam, frequentemente, os homens a praticar este tipo de violência, surgem da necessidade socialmente imposta de exercer o poder, conforme exposto ${ }^{6}$.

Todos os dias, milhares de mulheres são estupradas no mundo - grande parte delas dentro da própria casa. Segundo a Organização Mundial da Saúde (WHO, 2013: 2), estima-se que $35 \%$ das mulheres do planeta já tenham sofrido qualquer violência física e/ou sexual, praticada por parceiro íntimo, ou violência sexual por um nãoparceiro. Levantamento da UNICEF (2017: 73-82) revela que aproximadamente 15 milhões de adolescentes (de 15 a 19 anos) em todo o mundo experimentaram sexo forçado em algum momento de suas vidas. Na maioria dos países, as adolescentes

5 É possível, aqui, fazer a relação do processo de "nascimento do homem" com o da mulher, sintetizado pela filósofa Simone de Beauvoir na célebre frase "Ninguém nasce mulher, torna-se", presente na obra O Segundo Sexo (1949).

6 Sobre essa abordagem, ver também: Davis (2017). 
correm maior risco de serem forçadas a praticar sexo por um marido, parceiro ou namorado atual ou antigo.

Esses dados desconstroem facilmente o mito - resultado direto da infiltração do racismo nas posturas sociais - de que é mais provável que o estupro seja cometido por um homem negro. Segundo Angela Davis (2017), 9o\% dos estupros são intrarraciais, e não interraciais. Todavia, em razão do racismo historicamente presente na aplicação das leis, há, nas prisões, um número desproporcional de homens negros condenados por esse crime, quando comparado ao de homens brancos. Além disso, estudos sobre agressão sexual revelam que, tal como na época da escravidão, mais homens brancos estupram mulheres negras do que homens negros estupram mulheres brancas.

Para além da prática cotidiana da violência sexual nas sociedades patriarcais, ao longo dos anos, em contextos de guerras e ditaduras, triunfar sobre as mulheres pelo estupro tornou-se uma maneira de medir a vitória dos combatentes, parte da prova de masculinidade e de sucesso dos soldados.

Entre as primeiras civilizações da Grécia antiga, a violência sexual também era um comportamento socialmente aceitável dentro das regras da guerra, "um ato sem estigma para os guerreiros que viam as mulheres que conquistavam como pilhagem legítima, úteis como esposas, concubinas, trabalho escravo ou troféu de campo de batalha” (Brownmiller, 1993: 33). Segundo Brownmiller:

O estupro é mais do que um sintoma de guerra ou evidência de seu excesso violento. Estupro na guerra é um ato familiar com uma desculpa familiar. A guerra fornece aos homens o cenário psicológico perfeito para dar vazão ao seu desprezo pelas mulheres. A própria masculinidade dos militares - o poder bruto do armamento exclusivo de suas mãos, a ligação espiritual de homens armados, a disciplina viril de ordens dadas e ordens obedecidas, a lógica simples do comando hierárquico - confirma para os homens o que eles suspeitam por muito tempo, que as mulheres são periféricas, irrelevantes para o mundo que conta, espectadoras passivas para a ação no círculo central (1993: 32, tradução nossa ${ }^{7}$ ).

Em matéria divulgada pela Agência Brasil, em 2012, Chris Dolan, diretor de um projeto que dá assistência legal a refugiados congoleses em Uganda, afirma que os abusos sexuais são uma arma de guerra mais eficiente do que as convencionais, porque rompem a harmonia e o tecido social de uma comunidade. "Todas as relações entre os integrantes de uma família e dessa família com a vizinhança e com a sua

7 Original: "Rape is more than a symptom of war or evidence of its violent excess. Rape in war is a familiar act with a familiar excuse. Rape in war is a familiar act with a familiar excuse. War provides men with the perfect psychologic backdrop to give vent to their contempt for women. The very maleness of the military - the brute power of weaponry exclusive to their hands, the spiritual bonding of men at arms, the manly discipline of orders given and orders obeyed, the simple logic of the hierarchical commandconfirms for men what they long suspect, that women are peripheral, irrelevant to the world that counts, passive spectators to the action in the center ring". 
comunidade podem ser afetadas por um estupro" (Agência Brasil, 2012). Nesse sentido, homens de uma nação conquistada tradicionalmente veem o estupro de "suas mulheres" como a derradeira humilhação. Por tradição, eles se apropriam do estupro de "suas mulheres" como parte de sua própria angústia masculina de derrota (Brownmiller, 1993: 38).

Decorrem, ainda, do sentimento de impotência dos homens e do desprezo pelo feminino as frequentes mutilações genitais praticadas contra as vítimas em ataques com violência sexual. Por representarem uma constante ameaça ao poder do macho, mulheres são, todos os dias, subjugadas, controladas, silenciadas, mutiladas, e, muitas vezes, eliminadas.

\section{O gozo proibido e a culpa da mulher}

Erigida sobre bases profundamente desiguais e opressoras, a sociedade patriarcal não tolera a liberdade dos corpos femininos, sobretudo a sexual. Ao longo dos séculos, pesa sobre as mulheres todo tipo de repressão quanto à manifestação de sua sexualidade. O gozo é negado a elas, assim como o domínio de sua vida e de seus corpos. Socialmente, por exemplo, os pelos femininos são mais ofensivos, anti-higiênicos e obscenos do que os masculinos. O que justifica essa repulsão? Seria simplesmente o desacato a um modelo estético ou o incômodo gerado por uma mulher que decide expressar sua autonomia e romper um padrão estabelecido no contexto da erotização dos corpos femininos?

Ao longo do tempo, o cerceamento da liberdade sexual deste grupo tem sido um dos principais instrumentos de sustentação do patriarcado. Proibir e condenar a libido das mulheres, afastando-as de sua sexualidade, autonomia e possibilidades de realização, é uma forma eficiente de objetificá-las para servir aos desejos dos homens. Mas nem sempre foi assim. Conforme Muraro, se o ser humano habita a Terra há dois milhões de anos, mais de três quartos desse tempo ele viveu em agrupamentos matricêntricos, nos quais as mulheres eram livres para expressar a sexualidade como desejassem (Muraro, 1989: 11). Não é necessário, contudo, voltar a atenção ao passado para compreender que a repressão sexual e a inferiorização da mulher não representam algo "natural" ou "normal". Isso porque, ainda que raros, existem, na atualidade, exemplos de sociedades matricêntricas. Um deles é a tribo Mosuo, que vive no sudeste da China. Nela, as mulheres possuem total domínio de sua vida sexual e procriativa, conforme narrado no documentário Vivendo no matriarcado ${ }^{8}$. A liberdade sexual é garantida às integrantes da comunidade depois de um ritual de transição, no qual lhes é entregue a chave de um quarto privado, onde podem receber visitas masculinas durante a noite. Em vez do casamento, existe, portanto, a prática conhecida como tisese, termo traduzido como "indo e voltando", e que se refere ao

8 VIVENDO no matriarcado. Meteoro.doc. 2019 (14 min). Disponível em: <https://www.youtube.com/ watch?v=S-KeHwg2hh4\&t=1S $>$. Acesso em 20 maio 2019. 
costume de homens que vão à casa da mulher, passam a noite e voltam para onde moram, com as mães e parentes de sangue. Toda integrante da tribo pode praticar o tisese com quantos homens desejar, já que a cultura Mosuo não tem compromisso com a monogamia.

Essa realidade, porém, como dito, representa exceção no mundo contemporâneo. Em regra, a transformação da cultura matricêntrica em patriarcal, na maioria das sociedades, representou o cerceamento da liberdade da mulher em diferentes setores. No novo quadro social estabelecido pelo aparecimento da propriedade privada e dos direitos de herança, as mulheres, que até então ocupavam todos os espaços e expressavam-se sem limitações, ficam restritas ao âmbito doméstico e perdem qualquer capacidade de decisão no domínio público (Muraro, 1989: 13). Afinal, garantir a legitimidade da prole se tornou uma preocupação para os homens, e a liberdade sexual feminina representava um risco a esse objetivo.

Antes parteiras, curandeiras e detentoras de um saber feminino popular que era passado de geração a geração, as mulheres, aos poucos, vão se distanciando da libido, tida como uma ameaça aos direitos de família, e, portanto, objeto de permanente repressão.

Conforme Engels (1985), tanto para a religião quanto para o Estado, o ideal sempre foi o casamento procriador, capaz de fazer perpetuar a posse, a propriedade, o comércio e a economia. A reprodução é, consequentemente, encarada, ao longo da história, como a função primordial do sexo. Assim, a "mulher-mãe", a "mulheresposa", a "mulher-santa" não pode sentir prazer, o que é reservado à "mulherprostituta”, à "mulher-sensual", à "mulher-sentidos", que se coloca fora dos limites da família (Saffioti, 1989: 36). Com o surgimento do capitalismo, o controle da sexualidade humana, especialmente das mulheres, encontra terreno ainda mais fértil para se propagar, já que o domínio sobre os corpos é fundamental para se produzir trabalhadores dóceis, que vão ser alienados de seus trabalhos sem se rebelar, como constata Michel Foucault (2014) em seus estudos sobre o poder disciplinar e o biopoder. O gozo passa a ser visto como algo errado e proibido, de modo muito semelhante ao que ocorre na sociedade distópica, mas absolutamente verossímil, predita por George Orwell na obra 1984. Vale lembrar:

O Partido estava procurando matar o instinto sexual ou, se não fosse possível matá-lo, torcê-lo e torná-lo indecente. Ele [o personagem Winston] não sabia o porquê dessa conduta, mas assim era, e lhe parecia natural que assim fosse. E, no que se referia às mulheres, os esforços do Partido haviam logrado considerável êxito (ORWELL, 1983: 65).

Contudo, é com a caça às bruxas, no período que vai do fim do século XIV a meados do século XVII, na Europa, que se normaliza o comportamento das mulheres, por meio da repressão sistemática do feminino, e a culpa se torna presença constante na vida psíquica desse grupo. 
Pesquisadores estimam que entre quatro e cinco milhões de mulheres, pelos menos, consideradas hereges ou bruxas, foram queimadas vivas pelos tribunais da Inquisição, dirigida pela Igreja Católica Romana (Muraro, 1989: 18). Descritas como seres selvagens, com desejos insaciáveis, descontroladas e incontroláveis, as "bruxas" representavam o oposto do modelo de mulher passiva, dócil, obediente e submissa aos homens defendido pela Igreja e pelo Estado. Qualquer comportamento que destoasse desse padrão era cruelmente condenado. Até mesmo o tamanho do clitóris da mulher era justificativa para condená-la à fogueira. Qualquer prática sexual não reprodutiva era demonizada. Ao violarem um tabu, as "bruxas" se tornavam, elas mesmas, um tabu, uma ameaça à ordem econômica e religiosa e um convite à imitação que deveria ser eliminado.

É essa normatização da sexualidade feminina que até hoje mantém "mulheres livres", como as prostitutas, às margens do direito e que explica a inexistência de mecanismos jurídicos específicos para a proteção da integridade física dessas pessoas. Em relação a esses corpos, considerados dissidentes e abjetos pela sociedade, existe uma permissividade cultural ainda maior à violação.

Em alguns países da África, do Oriente Médio e do Sudeste Asiático, a eliminação do gozo feminino se dá pelo ritual de mutilação do clitóris e da parte externa dos órgãos genitais das mulheres. Feita, de modo precário, logo na infância, a extirpação leva muitas vítimas à esterilidade e à morte. Segundo a UNICEF (2016: 2), pelo menos 200 milhões de mulheres e meninas que vivem hoje sofreram mutilação genital nos 30 países com dados representativos sobre a prevalência. Na maioria desses países, a maior parte das meninas foi mutilada antes dos cinco anos de idade.

Em todo o mundo, contudo, tem sido o estupro o principal mecanismo de controle da sexualidade feminina. Sua presença milenar nas sociedades fez dele um fantasma entre as mulheres. Relata Brownmiller que Robert F. Murphy, do departamento de antropologia da Universidade de Columbia, estudou a prática na sociedade secreta masculina dos índios Mundurucu do Brasil central. Segundo Murphy, para os habitantes da tribo, quando a mulher, que deve ser dócil, submissa, obediente e fiel ao marido, é "abertamente promíscua e toma a iniciativa em relações sexuais", ela está manifestando comportamento apropriado apenas ao macho e, assim, invade e ameaça o papel masculino. Logo, "seus atos são vistos como um delito público, e sua punição [por meio do estupro] torna-se o dever adequado de todos os homens da aldeia" (Brownmiller, 1993: 286).

A crença na submissão feminina se perpetuou ao longo dos anos, de modo que, ainda hoje, as mulheres são culpabilizadas pela violência que sofrem. Figurando como uma ameaça à liberdade, o estupro se infiltra na consciência das meninas, desde muito pequenas, em graus imperceptíveis, como analisa Brownmiller:

Mesmo antes de aprendermos a ler, nos tornamos doutrinadas em uma mentalidade de vítima. Os contos de fada estão cheios de um temor vago, uma catástrofe que parece acontecer apenas com garotinhas. Doce e feminina, Chapeuzinho Vermelho está fora 
para visitar sua querida e velha avó na floresta. O lobo se esconde nas sombras, esperando para atacar. Chapeuzinho Vermelho e sua avó, aprendemos, são igualmente indefesas diante da força e da astúcia do lobo macho. Seus grandes olhos, suas grandes mãos, seus dentes grandes - "O melhor para ver você, para te pegar, para comer você, minha querida" O lobo engole as duas fêmeas sem sinal de luta. Mas entra o caçador - ele corrigirá esse fato abominável. A força e a astúcia do caçador gentil são superiores ao lobo. Com a torção de uma faca, Chapeuzinho Vermelho e sua avó são resgatadas de dentro do estômago do lobo. "Oh, estava tão escuro lá dentro", diz Chapeuzinho Vermelho. "Eu nunca mais vou vagar pela floresta enquanto eu viver" (Brownmiller, 1993: 309, tradução nossa9 ${ }^{9}$.

Para a autora, a história de Chapeuzinho Vermelho é uma parábola do estupro, que aponta a existência de figuras masculinas assustadoras nos bosques - os lobos e a impotência das mulheres diante deles. É melhor ficar perto do caminho e não ser aventureira, segundo a moral da história. E, se tiver sorte, a menina ou mulher pode encontrar um macho bom e amigável capaz de salvá-la de um desastre.

De forma semelhante, outros contos de fada também colocam a mulher na posição de passividade e de submissão. Bela Adormecida fica imóvel por cem anos até ser despertada pelo beijo do príncipe. Branca de Neve, em seu caixão de vidro, permanece paralisada até que seu príncipe apareça. E Cinderela, igualmente, precisa de um príncipe para tirá-la de seu ambiente miserável. Assim, a sexualidade feminina tem sido definida, amparando, por exemplo, a crença popular de que o estupro de uma mulher decorre de algum comportamento imprudente adotado por ela mesma, ou de que as mulheres desejam ser dominadas e sentem prazer nisso, ideia abalizada pela teoria psicanalítica de Sigmund Freud e enfaticamente criticada por Brownmiller e por outras autoras feministas. Para Brownmiller, "a crença no sonho de estupro inconsciente implica a crença em um desejo inerente de estupro por parte de todas as mulheres - uma falsa suposição que os analistas freudianos de hoje e os criminologistas de estilo freudiano continuam a perpetuar" (Brownmiller, 1993: 322). Conforme a autora, a fantasia de estupro existe nas mulheres como "um iceberg criado pelo homem”. Não representa, assim, o produto da mente de uma mulher saudável. Pode - e deve -, portanto, ser destruída pelo feminismo.

9 Original: "Even before we learn to read we have become indoctrinated into a victim mentality. Fairy tales are full of a vague dread, a catastrophe that seems to befall only little girls. Sweet, feminine Little Red Riding Hood is off to visit her dear old grandmother in the woods. The wolf lurks in the shadows, contemplating a tender morsel. Red Riding Hood and her grandmother, we learn, are equally defenseless before the male wolf's strength and cunning. His big eyes, his big hands, his big teeth-"The better to see you, to catch you, to eat you, my dear." The wolf swallows both females with no sign of a struggle. But enter the huntsman-he will right this egregious wrong. The kindly huntsman's strength and cunning are superior to the wolf's. With the twist of a knife Red Riding Hood and her grandmother are rescued from inside the wolfs stomach. 'Oh, it was so dark in there,' Red Riding Hood whimpers. 'I will never again wander off into the forest as long as I live'. Red Riding Hood is a parable of rape." 
Sobre a influência da teoria freudiana na construção da ideia de passividade feminina, Fuentes observa:

A sexualidade da menina teria sido concebida por Freud no seio de uma cultura preconceituosa, que deu margem à valorização não justificada do pênis (e sua inveja), bem como ao poder do patriarcado que se queria conservar. Simone de Beauvoir e Kate Millet destacam-se na denúncia de que a teoria freudiana seria datada pela Viena fin-de-siècle, e que a inveja do pênis e o masoquismo feminino resumir-se-iam à opressão do patriarcado, que mobilizaria a insatisfação feminina diante do seu inexpressivo lugar na sociedade. Ou seja, o que se invejava eram os benefícios do homem e não o pênis em si (Fuentes, 2019: 60).

A análise da inferiorização da mulher na sociedade, da violência sexual e da repressão ao gozo feminino precisa ser realizada, ainda, com atenção especial às peculiaridades étnicas e raciais. Situadas na intersecção entre racismo, sexismo e injustiça econômica, como observa Angela Davis, as mulheres negras vêm sendo submetidas a um processo opressivo ainda mais complexo do que as brancas. No Brasil, em 2019, 50,9\% das vítimas de violência sexual eram negras e 48,5\% brancas (FBSP, 2019: 7). A letalidade da violência é maior também neste grupo. Em 2017, por exemplo, 66\% das 4.936 mulheres mortas no Brasil eram negras, e esse índice vem crescendo, conforme demonstra o último Atlas da Violência. Entre 2007 e 2017, a taxa de homicídios das mulheres negras aumentou 29,9\%, enquanto a das não negras aumentou 1,6\%. Com essa variação, a taxa de homicídios de mulheres negras chegou a 5,6 para cada 100 mil em 2017, enquanto a de mulheres não negras foi de 3,2 por 100 mil (IPEA, 2019: 38).

Por se sentirem sempre, de alguma forma, culpadas pelos atos de violência sofridos e por temerem os julgamentos sociais, as mulheres - sejam negras, brancas, índias, jovens, idosas, ricas ou pobres - padecem em silêncio e tendem a não denunciar seus agressores, o que favorece a perpetuação da violência contra elas.

Neste contexto de construções sociais tão opressoras sobre o gênero e sobre a raça, há tanto tempo cristalizadas nas sociedades patriarcais, é preciso enfrentar o paradoxo da criminalização da violência sexual contra a mulher e da simultânea permissividade cultural à subjugação feminina. É possível esperar que o problema da violência contra a mulher seja resolvido com base apenas no Direito, especialmente o Direito Penal?

\section{Criminalização $x$ permissividade}

Durante muito tempo, as diversas formas de violência contra a mulher (não apenas sexual, mas também física, moral, psicológica e patrimonial, previstas, no 
Brasil, pela Lei 11.340/2006 - Lei Maria da Penha) não eram condenáveis moral ou criminalmente. Ao contrário disso, como se viu, no que diz respeito à violência sexual, o estupro representava uma recompensa aos guerreiros vitoriosos em combates. Filhas virgens eram negociadas pelos seus pais como mercadorias, com vistas à ampliação do patrimônio familiar.

A criminalização da violência sexual contra a mulher, quando ocorre, no Velho Testamento, não intenciona proteger as vítimas, como se poderia pensar, mas os negócios do patriarca, já que o ato era visto como uma afronta à propriedade privada. Segundo Brownmiller, o estupro entrou na lei pela "porta dos fundos", como um crime de propriedade de um homem contra outro homem. Assim:

O estupro criminoso, como o pai patriarcal o via, era uma violação do novo modo de fazer negócios. Era, em uma frase, o roubo da virgindade, um desfalque do preço justo de sua filha no mercado. Cerca de quatro mil anos antes, o Código de Hamurabi, lascado em uma coluna de pedra de diorito de dois metros e meio, deixava claro por suas omissões que a uma mulher não era permitido nenhum status independente sob a lei babilônica. Ela era uma virgem prometida, morando na casa de seu pai, ou então ela era alguém legalmente casada (BROWNMILLER, 1993: 18, tradução nossa $\left.{ }^{10}\right)$.

Somente a partir dos séculos XVI eXVII, o estupro começa a ser percebido como um ato de violência, mas, também neste período, sua criminalização não buscava proteger a dignidade da mulher. O que se via ameaçada e digna de preservação era a honra da família, que poderia se desmantelar com o "roubo da castidade e da virtude" da vítima (Rossi, 2016: 42).

No curso das mudanças históricas, a concepção sobre a violência sexual vem se modificando, e é somente a partir da segunda metade do século XX, com a pressão dos movimentos feministas, que as discussões avançam no sentido de proteger a mulher como sujeito de direitos. Até então, o Direito - manifestação normatizada da moralidade e do pensamento masculinos -, prestou-se, em quase todo o mundo, apenas a afirmar, codificar e institucionalizar a mentalidade patriarcal.

Assim, no Brasil, o Código Criminal do Império, de 1830, classificava o estupro como crime contra a "segurança da honra". No Código de 189o, o ato foi considerado um crime contra a "segurança da honra e honestidade das famílias". E em 1940, firmou-se no Código Penal como um crime contra os "costumes".

10 Original: "Criminal rape, as a patriarchal father saw it, was a violation of the new way of doing business. It was, in a phrase, the theft of virginity, an embezzlement of his daughter's fair price on the market. About four thousand years ago the Code of Hammurabi, chipped on a seven-foot column of diorite stone, made plain by its omissions that a female was allowed no independent status under Babylonian law. She was either a betrothed virgin, living in the house of her father, or else she was somebody's lawfully wedded." 
Em 1990, a Lei 8072/90 reconheceu o estupro como crime hediondo" ${ }^{\text {. No }}$ entanto, até o advento da Lei 11.106, de 2005, o casamento do autor do crime com a vítima, e até mesmo o casamento da vítima com terceiros, em alguns casos, era expressamente previsto como causa de extinção de punibilidade (IENNACO, 2017: 188).

Somente em 2009, a Lei 12.015 alterou o Título VI do Código Penal Brasileiro, que passou a tutelar a "dignidade sexual", e não mais os "costumes". A lei conferiu, também, nova redação ao artigo 213 do Código Penal, definindo o estupro como o ato de "constranger alguém, mediante violência ou grave ameaça, a ter conjunção carnal ou a praticar ou permitir que com ele se pratique outro ato libidinoso". Atualmente, a pena para este crime no Brasil é de seis a 10 anos de reclusão, aumentando para oito a 12 anos se há lesão corporal da vítima ou se a vítima possui entre 14 a 18 anos de idade, e para 12 a 30 anos, se a conduta resulta em morte.

Outros marcos legislativos relevantes no combate à violência contra a mulher foram a Lei Maria da Penha (Lei 11.340/o6), publicada em 2006, que passou a tratar o problema sob a ótica da desigualdade de gênero, e a Lei do Feminicídio (Lei 13.104/15), de 2015, que qualificou o crime de homicídio quando a vítima é assassinada pelo fato ser mulher.

No entanto, apesar dos avanços na legislação em direção à proteção das mulheres e ao endurecimento da punição dos agressores, a permissividade à violação da liberdade sexual feminina ainda é marca viva na mentalidade e no cotidiano sociais, manifestando-se, diariamente, das mais diversas formas, nos âmbitos público e privado.

Em uma pesquisa realizada com um grupo de detentos do Complexo Penitenciário da Papuda, no Distrito Federal, condenados por estupro, a antropóloga Rita Laura Segato identificou significantes importantes e pouco abordados das relações de gênero, que se relacionam intimamente com a violência sexual. Dentre as principais constatações do estudo está a de que a prática do estupro resulta, em grande medida, de um "mandato de violação" exercido pelo agressor a fim de comunicar seu status de "homem”, ou mais precisamente, sua virilidade, característica exigida, continuamente, dos sujeitos masculinos nas sociedades patriarcais (Segato, 2003: 256). Desse modo, segundo a autora, este tipo de violência cumpre funções que ultrapassam o corpo da vítima, apresentando natureza mais expressiva (que deseja simbolizar algo) do que instrumental (que intenta realizar algo).

O ato violento revela-se, assim, como a condição necessária para a reprodução do gênero como estrutura de relações entre posições marcadas pelo diferencial hierárquico. Segato (2003: 254) sugere tratar-se de uma espécie de "mais-valia de gênero", que se baseia na subalternidade do feminino.

11 Embora tenha incluído o estupro na lista dos crimes hediondos, a Lei 8072/90 deu margem a controvérsias acerca de quais modalidades do delito estavam sendo consideradas, o que só foi esclarecido com a edição da Lei 12.015/o9, que afirmou a hediondez tanto das modalidades simples como das qualificadas. 
Ao analisar a fala dos entrevistados, a antropóloga constatou ser comum a presença de um discurso "moralizador, disciplinador" sobre o comportamento das mulheres. De acordo com ela, o estupro é percebido pelos violadores "como castigo ou vingança contra uma mulher genérica que saiu do seu lugar, isto é, de sua posição subordinada e ostensivamente tutelada por um sistema de status".(...) Um dos entrevistados afirmou à autora que "só a mulher crente é boa", o que significa dizer que "só ela não merece ser violentada" (Segato, 2003: 21). Outros temas recorrentes nos relatos sugerem o estupro como agressão ou afronta contra outro homem também genérico e como demonstração de força e virilidade para uma comunidade de pares.

A delimitação da posição a ser ocupada pelas mulheres pode ser vista, cotidianamente, também nas instituições de justiça. Na contramão das leis que vêm buscando zelar pela liberdade sexual feminina, o mundo jurídico apresenta-se, ainda, como espaço de predominância de valores masculinos, cumprindo, historicamente, um papel significativo na manutenção da ordem de status entre homens e mulheres. Não são raras as manifestações e decisões eivadas de estereótipos de gênero e de concepções discriminatórias em relação à mulher, a revelarem um quadro patente de desarmonia entre os propósitos da lei e a moralidade patriarcal ainda arraigada na mentalidade de operadores do Direito.

Um emblema dessa realidade é o caso de um juiz do município de Sete Lagoas, em Minas Gerais, que, em 2007, em sentença sobre a aplicabilidade da Lei Maria da Penha, em que não deferia as medidas protetivas de urgência, defendeu a superioridade masculina, argumentando que "o mundo é masculino" e que "Jesus foi homem”. À época, o magistrado sustentou que a Lei Maria da Penha corresponde a "um conjunto de regras diabólicas", como se vê no seguinte trecho da decisão:

PROCESSO ADMINISTRATIVO DISCIPLINAR ooo537072.2009.2.00.0000 (200910000053701) . Esta "Lei Maria da Penha" - como posta ou editada - é, portanto, de uma heresia manifesta. Herética porque é antiética; herética porque fere a lógica de Deus; herética porque é inconstitucional e por tudo isso flagrantemente injusta. Ora! A desgraça humana começou no éden: por causa da mulher -todos nós sabemos -mas também em virtude da ingenuidade, da tolice e da fragilidade emocional do homem. Deus então, irado, vaticinou para ambos. E para mulher, disse: "[...] o teu desejo será para o teu marido, e ele te dominará. [...] Por isso - e na esteira destes raciocínios - dou-me o direito de ir mais longe, e em definitivo! O mundo é masculino! A ideia que temos de Deus é masculina! Jesus foi Homem![...] Porque a vingar este conjunto normativo de regras diabólicas, a família estará em perigo, como inclusive já está: desfacelada, os filhos sem regras-porque sem pais; o homem subjugado; sem preconceito, como vimos, não significa sem ética -a adoção por homossexuais e o "casamento" deles, como mais um exemplo. Tudo em nome de uma igualdade cujo conceito tem sido prostituído em nome de uma "sociedade igualitária". Não! O 
mundo é e deve continuar sendo masculino, ou de prevalência masculina, afinal (CNJ, 2011).

Diante da repercussão do caso, o Conselho Nacional de Justiça (CNJ) - acionado pela Secretaria de Políticas para as Mulheres a se manifestar - decidiu suspender o juiz do cargo, em razão do caráter sexista de sua decisão, absolutamente contrária ao princípio básico de garantia do direito humano das mulheres a uma vida livre de violência. Contudo, menos de dois anos depois, o Ministro do STF Marco Aurélio Mello considerou o afastamento "inadequado", cancelou a punição e determinou o retorno do Magistrado à ativa. Ele argumentou pela "defesa da liberdade do pensamento dos magistrados", sustentando que as afirmações do juiz foram feitas de forma "abstrata" e que correspondem a uma "concepção individual", evidenciando, assim, a complacência do Judiciário - ou de parte significativa dele - com a postura do juiz.

O olhar permissivo de parte dos Magistrados sobre a violação da liberdade sexual da mulher, resultante do sexismo que constitui a sociedade brasileira, constitui, certamente, um impasse ante a criminalização dos atos de violência sexual. Neste sentido, o perfil dos juízes que atuam no combate à violência contra as mulheres pode ser determinante para uma correta aplicação da lei. Isso porque, conforme ensina Donna Haraway (2009), o olhar humano é corporificado e localizado, ou seja, as traduções que os indivíduos fazem do mundo e o conhecimento que produzem a partir delas são influenciados pela posição que ocupam neste mesmo mundo, variam conforme experiências, aprendizados, interesses e necessidades e estão intrinsecamente conectados com as estruturas e relações de poder que envolvem as pessoas.

Para além das tensões presentes nos tribunais entre a criminalização da violência sexual contra as mulheres e a permissividade cultural em relação a essa prática, é possível ver, recorrentemente, também no meio político, mostras clara do menosprezo do feminino e da complacência quanto à subjugação sexual das mulheres. Exemplo recente dessa realidade foi dado pelo atual presidente do Brasil, Jair Bolsonaro, que, em entrevista à imprensa, condenou o turismo gay no país e incentivou a exploração sexual feminina, ao declarar: "Quem quiser vir aqui fazer sexo com uma mulher, fique à vontade" (Pragmatismo Político, 2019).

A fala de Bolsonaro, assim como as lentes machistas utilizadas por muitos operadores do Direito em sua atuação, infelizmente, parecem refletir o pensamento de uma parte considerável dos brasileiros. Segundo estudo de abrangência nacional divulgado pelo Ipea em 2014, 26\% dos entrevistados concordaram inteiramente (13,2\%) ou parcialmente $(12,8 \%)$ com a frase "Mulheres que usam roupas que mostram o corpo merecem ser atacadas”, enquanto $58,4 \%$ discordaram totalmente, $11,6 \%$ discordaram parcialmente e $3,4 \%$ se declararam neutros. E, ainda, 58,5\% concordaram totalmente $(35,3 \%)$ ou parcialmente $(23,2 \%)$ com a frase "Se as mulheres soubessem como se comportar, haveria menos estupros”. Os que discordam totalmente da afirmação 
foram 30,3\% e parcialmente, $7,6 \%$, enquanto 3,6\% se disseram neutros em relação à questão (IPEA, 2014).

É dessa objetificação das mulheres, aspecto estrutural da cultura brasileira, que decorrem as centenas de estupros diários registrados no país e os milhares, em todo o mundo. Importante não perder de vista a expressiva ocorrência desses crimes dentro das relações conjugais e a subnotificação dos abusos, resultado do silêncio gerado pela culpa, pela vergonha e pelo medo sentidos pelas vítimas.

Pelo que demonstram a história e a contemporaneidade, o Direito não tem dado conta de estancar a violência de gênero. Ao contrário, a impressão atual é que o afrontamento às estruturas patriarcais, pelo reconhecimento dos direitos das mulheres, tem resultado em reações "hipervirilistas" e no consequente aumento dos casos de agressões. Diante da força exercida pela cultura patriarcal, qual tem sido o papel do Direito Penal? Pode ele modificar estruturas de poder milenares?

Considerando o alarmante número de mortes de mulheres em razão do gênero, no Brasil e no mundo, e também de pessoas LGBTQIA+, a sociedade contemporânea não pode prescindir, ainda, do regramento penal para abordar os casos mais graves de violência e para proteger as vítimas. É preciso considerar também a existência de um poder simbólico na punição dos agressores, que por tanto tempo agiram impunemente, encarando a opressão como algo natural.

No entanto, parece cada vez mais claro que somente uma mudança profunda nas estruturas de poder poderá, de fato, conter o quadro de violência de gênero nas sociedades patriarcais. No contexto brasileiro, não se pode perder de vista os aspectos históricos e culturais que constituíram a nação, sobretudo a partir do violento processo de colonização capitaneado pelos portugueses. A política de expansão adotada por Portugal em sua colônia, a fim de impedir a tomada do território pelos espanhóis, foi implementada sob o triste signo do estupro cotidiano, corriqueiro e impune de indígenas e africanas. A violência sexual contra a mulher encontra-se, portanto, inscrita no tecido social brasileiro há mais de 500 anos.

A modificação de uma estrutura tão antiga só pode se dar, portanto, por meio da educação, do debate incessante sobre o tema nas diferentes esferas sociais, como escolas, universidades, igrejas e instituições públicas, e da compreensão cada vez mais aprofundada sobre gênero e sexualidade.

\section{Considerações finais}

Como se viu, o tratamento dado pelo Direito Penal ao crime de estupro no Brasil foi se modificando ao longo dos anos. Da completa omissão sobre a dignidade sexual da mulher ao reconhecimento da natureza hedionda do ato e ao endurecimento da pena aos agressores, a legislação avançou no sentido de proteger as vítimas. Contudo, diante de mais de cinco séculos de inferiorização da mulher no país, a permissividade à violação aos direitos deste grupo ainda é uma realidade na sociedade brasileira, ao 
ponto de ainda existirem inúmeros homens que tratam esposas, namoradas e filhas como objetos, dos quais seriam "proprietários" e, portanto, detentores do poder de controle sobre os comportamentos e destinos dessas mulheres.

Para combater o estupro e as demais formas de violência contra a mulher, a discussão sobre gênero na sociedade é caminho inafastável e urgente. É preciso promover reflexões sobre masculinidades e feminilidades, sobre a formação da subjetividade e da autonomia do ser, sobre suas potencialidades de realização, sobre a construção de novos homens, de novas mulheres e de novas formas de se relacionar.

Nos núcleos familiares, é fundamental que mulheres e homens redesenhem, no exercício da maternidade e da paternidade, os ensinamentos transmitidos aos seus filhos e filhas desde cedo, de forma a se evitar a perpetuação da tradicional e nociva educação discriminatória de gênero. Somente assim será possível romper a lógica de que, para ser respeitada, a mulher deve cumprir os papéis sociais estabelecidos para ela. E, da mesma forma, de que, para ser homem, é preciso seguir os "mandamentos" da masculinidade agressiva e dominadora.

O abandono do esforço diário para se autoafirmar viril ou "macho", que de forma tão marcante caracteriza o cotidiano dos sujeitos masculinos, poderá favorecer o deslocamento dessa energia para campos efetivamente propícios à construção da paz e da justiça social, como o da afetividade, e, consequentemente, promover verdadeiras revoluções na vida dos homens, das mulheres e da sociedade.

\section{Referências}

AGÊNCIA BRASIL. (2012). "No Congo, 48 mulheres são estupradas a cada hora". Agência Brasil. Disponível em: <http://memoria.ebc.com.br/agenciabrasil/ noticia/2012-o8-24/no-congo-48-mulheres-sao-estupradas-cada-hora>. Acesso em: 12 jul. 2019.

BROWNMILLER, Susan. (1993). Against our will: men, women and rape. New York: Ballantine Books.

CASAGRANDE, Maria Clara B. O.; OLIVEIRA, Ana Claudia D. C. de; REBELLO, Luis Felipe. (2015). "Os estupros como arma de guerra contra as mulheres durante a guerra na Bósnia-Herzegovina (1992-1995): Uma reflexão à luz do conceito de segurança humana das Nações Unidas”. Revista Ártemis, v. 20: p. 128-140, ago-dez. Disponível em $<$ https://periodicos.ufpb.br/index.php/artemis/article/view/27052/14411>. Acesso em: 26 jun. 2020.

DAVIS, Angela. (2017). Mulheres, cultura e política. Tradução de Heci Regina Candiani. São Paulo: Boitempo. 
ENGELS, F. (1985). A origem da família, da propriedade privada e do Estado. 10 ${ }^{\mathrm{a}} \mathrm{ed}$. Rio de Janeiro: Civilização Brasileira.

FOUCAULT, Michel. (2014). História da Sexualidade: A vontade de saber (Vol. 1). São Paulo: Paz e Terra.

FBSP - Fórum Brasileiro de Segurança Pública. (2019). Anuário Brasileiro de Segurança Pública. Disponível em: <http://www.forumseguranca.org.br/publicacoes/13anuariobrasileiro-de-seguranca-publica>. Acesso em: 20 jun. 2020.

FUENTES, Maria Josefina Sota. (2019). As mulheres e seus nomes: Lacan e o feminino. Tese (Doutorado em Psicologia) - Programa de Pós-Graduação em Psicologia, Instituto de Psicologia da Universidade de São Paulo, São Paulo.

HARAWAY, Donna. (2009). Saberes localizados: a questão da ciência para o feminismo e o privilégio da perspectiva parcial. Cadernos Pagu, n. 5: p. 7-41, jan.

HEFEZ, Serge. (2013). Homens no divã. Tradução Iraci D. Poleti, Regina Salgado Campos. $1^{\mathrm{a}}$ ed. São Paulo: Benvirá.

HRW - Human Rights Watch. (2015). "Justice on Trial: Lessons from the Minova Rape Case in the Democratic Republic of Congo". Disponível em: <https://www.hrw. org/report/2015/10/o1/justice-trial/lessons-minova-rape-case-democratic-republiccongo $>$. Acesso em: 3 maio 2019.

IENNACO, Rodrigo. (2017). Crimes culturalmente motivados e violência sexual contra a mulher. Belo Horizonte: Editora D’Plácido.

IPEA - Instituto de Pesquisa Econômica Aplicada. (2014). Tolerância social à violência contra as mulheres. Brasília, Rio de Janeiro, São Paulo: Instituto de Pesquisa Econômica Aplicada; São Paulo: Fórum Brasileiro de Segurança Pública. Disponível em: <http://www.ipea.gov.br/portal/images/stories/PDFs/SIPS/140327_sips_violencia_ mulheres_novo.pdf >. Acesso em: 3 maio 2019.

- (2018). Atlas da violência 2018. Brasília, Rio de Janeiro, São Paulo: Instituto de Pesquisa Econômica Aplicada; São Paulo: Fórum Brasileiro de Segurança Pública. Disponível em: <http://www.ipea.gov.br/portal/images/stories/PDFs/relatorio_ institucional/180604_atlas_da_violencia_2018.pdf>. Acesso em: 3 maio 2019.

. (2019). Atlas da violência 2019. Brasília, Rio de Janeiro, São Paulo: Instituto de Pesquisa Econômica Aplicada; São Paulo: Fórum Brasileiro de Segurança Pública. Disponível em: <https://www.ipea.gov.br/portal/images/stories/PDFs/relatorio_ institucional/190605_atlas_da_violencia_2019.pdf>. Acesso em: 6 ago. 2020. 
MURARO, Rose Marie. (1989). A repressão dos valores femininos no mundo e na igreja - pontos para uma reflexão teológica. In: Mulher e Dignidade, dos mitos à libertação. São Paulo: Paulinas.

ORWELL, George. (1983). 1984. São Paulo: Editora Nacional.

PLUMMER, Ken. (1984). The social uses ofsexllality: symbolic interaction, power andrape. In: June Hopkins (comp.). Perspectives on Rape and Sexual Assault. Londres: Harper and Row.

PRAGMATISMO POLÍTICO. (2019). “'Quem quiser vir ao Brasil fazer sexo com mulher, fique à vontade', diz Bolsonaro”. Pragmatismo político. Disponível em: <https:// www.pragmatismopolitico.com.br/2019/o4/jair-bolsonaro-brasil-paraiso-gay.html>. Acesso em: 20 jun. 2020.

ROSSI, Giovana. (2016). A culpabilização da vítima no crime de estupro: os estereótipos de gênero e o mito da imparcialidade jurídica. Florianópolis: Empório do Direito.

SAFFIOTI, Heleieth. (1989). Relações de gênero: violência masculina contra a mulher in Mulher e Dignidade, dos mitos à libertação. São Paulo: Paulinas. . (2001). O poder do macho. São Paulo: Moderna. (Coleção Polêmica).

SCOTT, Joan Wallach. (1995). "Gênero: uma categoria útil para a análise histórica" Educação E Realidade, n. 2, v. 20: p.71-99, jul-dez.

SEGATO, Rita Laura. (2003). Las Estruturas Elementares de la violência: ensayos sobre gênero entre la antropologia, o psicoanalisis y los derechos humanos. Buenos Aires: Universidad Nacional de Quilmes/ Prometeo.

THE TESTIMONY. Direção de Vanessa Block. Estados Unidos: Escape Artists, (2015). 1 DVD (28 min.), son., color.

UNICEF. (2017). A Familiar Face: Violence in the lives of children and adolescents. Nova Iorque: UNICEF.

(2016). Female Genital Mutilation/Cutting: A global concern. Disponível em: <https://www.unicef.org/media/files/FGMC_2016_brochure_final_UNICEF_ SPREAD.pdf $>$. Acesso em: 20 jun. 2019. 
WORLD Health Organization [WHO]. (2013). Department of Reproductive Health and Research, London School of Hygiene and Tropical Medicine, South African Medical Research Council. Global and regional estimates of violence against women: prevalence and health effects of intimate partner violence and non-partner sexual violence. Disponível em: <https://www.who.int/reproductivehealth/publications/ violence/9789241564625/en/>. Acesso em: 3 maio 2019.

Recebido em 13/08/2019.

Aceito em 14/o8/2020. 